\title{
Research on the Problem of Internal Control Evaluation of Listed Companies
}

\author{
ShouChun Xiong \\ Huaiyin Institute of Technology \\ Huaian 223003, Jiangsu, China
}

\begin{abstract}
Internal control evaluation is an important process of internal control of listed companies. Its purpose is to measure the effectiveness of the implementation of internal control system. It is an important measure to perfect and optimize the internal control system. Due to the internal control evaluation with late start and poor foundation in China, there are still many problems in internal control evaluation of listed companies. Based on the analysis of the internal control evaluation work of listed companies, this paper discusses the problems existing in the internal control evaluation of listed companies, and puts forward corresponding countermeasures on how to improve the internal control evaluation work of listed companies.
\end{abstract}

Keywords-Internal control evaluation system; Internal control evaluation system; Evaluation personnel quality of listed companies

\section{INTRODUCTION}

Internal control is implemented by the company's board of directors, supervisory board, manager level, and all employees to achieve the control goal. Internal control is very important for listed companies. It has an important influence on enterprises to improve their management level, improve their risk defense capabilities, and maintain the public. Internal control evaluation, as an important institutional arrangement to optimize the internal control self-supervision mechanism of listed companies, is a resource component of the internal control system. According to the second article of the "Guidelines for Internal Control Evaluation of Enterprises", internal control evaluation of enterprises refers to the process by which the board of directors or similar authority of an enterprise conducts a comprehensive evaluation of the effectiveness of internal control, forms a comment conclusion, and issues an evaluation report. For listed companies, internal control evaluation helps them to improve their internal control system, improve their market image and public recognition.

\section{CURRENT SituATION OF INTERNAL CONTROL EVALUATION OF LISTED COMPANIES}

There is a certain gap between internal control evaluation of listed companies in our country and foreign countries. The reason is that China has begun to study internal control evaluation of listed companies relatively late, there is no certain foundation, and it is entirely from scratch, slowly exploring the system suitable for internal control evaluation of listed companies in our country. Generally speaking, the quality of internal control evaluation in China is not high.
Before the absence of specific internal control evaluation system, the internal control evaluation of many listed companies in China was missing, resulting in huge losses to the company. For example, in 2004, AVIC Singapore Company should engage in speculative activities that caused a huge loss of 554 million U.S. dollars; Huaxia Securities Company was ordered to stop securities business activities and other incidents in 2005. The reasons for the losses suffered by these companies vary, but the main reason is to ignore the role of internal control.

Influenced by the promulgation of laws and regulations on the internal control of listed companies abroad, China issued the Basic Standards for Internal Control of Enterprises in June 2008, and all provinces and industries throughout the country have conducted internal control evaluation training. The internal control evaluation work is carried out in China. This basic norm integrates the advantages of foreign related internal control system, and combines with the specific situation of internal control evaluation of listed companies in China. This norm is suitable for the development needs of listed companies in China, and it also marks the new stage for the study of internal control evaluation in China. However, due to the relatively late start of the internal control evaluation of listed companies in China, there is no theoretical basis, there are many problems. Taking the internal control index of listed companies in China as an example in 2016, 512 listed companies disclosed a total of 4,447 internal control defects. Among them, 61 major defects accounted for $1.37 \%, 4332$ important defects accounted for $97.41 \%$, and 54 general defects accounted for $1.21 \%$. Therefore, China needs to strengthen the internal control evaluation of listed companies. In the internal control evaluation of listed companies, we must not relax, to strengthen its research, only in this way, so that the healthy development of listed companies [1].

\section{PRoblems In INTERNAL CONTROL EVAluation OF LISTED COMPANIES}

\section{A. Not paying attention to the internal control evaluation of listed companies}

Due to the late start of the internal control evaluation work, the foundation is poor, and it is easily ignored in the implementation and is not valued. There are several specific aspects as follows. First of all, in the implementation of internal control evaluation, some departments believe that 
internal control is only an internal control department matter, and that internal control evaluation work is self-fault, is nothing to find trouble behavior, resulting in them will not actively cooperate with the listed company internal control evaluation work. Secondly, in the absence of understanding the specific role of internal control evaluation, in the absence of incentives and sanctions measures, internal control evaluation staff will often disguise the existing problems, easy to cause the internal control evaluation report has an untrue situation. Finally, many listed companies set up a number of internal control departments, resulting in lack of communication, resulting in the company's failure to perform internal control evaluation work in a timely manner.

After investigation, the internal control evaluation of listed companies in China is divided into the following centralized implementation. $58.54 \%$ of listed companies are fully responsible for internal control evaluation by the internal audit department. In the internal control evaluation work, the internal audit department has great limitations. Without the support of the company's first leader, the internal audit department can not fully carry out the internal control evaluation work. 35.36 per cent of listed companies cooperate with departments dealing with internal control, in which case it is often difficult to form a unified view, as there are often different sectors. $3.66 \%$, internal control evaluation work only focuses on the financial department, resulting in internal control evaluation work only around the financial, so that the internal control evaluation report is not comprehensive. $2.44 \%$ of enterprises are led by the Ministry of Risk and the Ministry of Strategy to carry out internal control evaluation, which can lead to false internal control evaluation reports [2].

\section{B. Deficiencies in the internal control evaluation system of listed companies}

The internal control evaluation system of listed companies is unreasonable, and there are problems in two aspects. First, internal control evaluation report disclosure information is not standardized. The lack of uniform rules on the time, index and format of internal control evaluation reports of listed companies in our country leads to a variety of internal control evaluation reports issued by listed companies, which is not conducive to comparison, can not find the internal control problems in time, and puts forward corresponding solutions. The effectiveness of internal control of listed companies is more important to its development. The internal control evaluation results can well reflect the effectiveness of internal control of listed companies. Each listed company will adopt more and less bad methods for its own interests, which can easily lead to the issuance of internal control evaluation reports. Although there is no fraud, the content of the reports is not comprehensive, and it is not helpful for listed companies to establish effective internal control. Secondly, the internal control evaluation of listed companies failed to disclose information in time. In particular, information that is unfavorable to the enterprise is mainly concealed by means of delayed disclosure, vague disclosure, selective disclosure, and even non-disclosure. For example, taking Heilongjiang Northland Company as an example, Heilongjiang Northland Agricultural Co., Ltd. was announced in 1998. In 2002,
Heilongjiang Northland Company was officially listed on the Shanghai Stock Exchange. In 2012, the following incidents occurred in the company, where internal control and evaluation staff failed to meet their disclosure obligations in a timely manner, resulting in losses to the company. In 2012, the holding subsidiary, Longyu Malt Company, divided the loan funds into two times to Qinhuangdao Hongqi Real Estate Development Co., Ltd. 20 million yuan, and the internal control and evaluation staff did not disclose it in time; Because the company's production and operation require funds, the company's controlling shareholder, Beidaola Group, has accumulated a total of 80 million yuan in loan funds; Due to the demand for funds, the subsidiary of Beidaola Group, Geqiashan Farm, required the guarantee company to be 11 million yuan. The internal control and evaluation staff did not disclose it in time.

\section{The quality of personnel engaged in internal control evaluation of listed companies is not high}

The quality of internal control and evaluation staff of listed companies will have a major impact on the quality of evaluation work. Generally speaking, the quality of internal control and evaluation personnel of listed companies in China is not high, and to a certain extent, it can be described in terms of business and moral quality.

First of all, internal control and evaluation staff in the business quality is not high. The internal control evaluation work has high requirements for the professional ability of personnel, but in the actual work, the professional competence of most internal control evaluation personnel is not enough. Many companies did not explicitly serve as qualification requirements for internal control evaluation staff when selecting internal control evaluation personnel. Considering that knowledge of finance, audit and management is sufficient and that the threshold is low, which makes it impossible for many non-professional personnel to perform internal control evaluations, resulting in inadequate internal control and evaluation staff, Lead to dereliction of duty or even major mistakes in the work, causing major losses to the company. Secondly, the internal control evaluation staff moral quality needs to be improved. The internal control evaluator may be influenced by the company's management and can not carry out the evaluation work impartially and objectively. He may even produce a false evaluation report against his will under the pressure of the management. He may also be fraudulent because of his own economic interests. In order to obtain benefits, Abandon principles and professional ethics to engage in illegal operations. The internal control evaluation report is not true, and even deliberately falsifies, damaging the interests of the company and the public [3]. 


\section{MEASURes to IMPRove THE INTERnAl CONTROL EVALUATION OF LISTED COMPANIES}

\section{A. Paying attention to the internal control evaluation of listed companies}

The main body of internal control evaluation should be the board of directors or similar power organs. We can refer to the successful experience of the West and abroad. In light of China's National conditions, the board of directors can appoint an audit committee to assume the responsibility of organizing, leading, and supervising the evaluation of internal control. Each department is responsible for the authenticity of the internal control evaluation report, and all departments should take the evaluation work seriously. The audit committee, the management level, and even the board of directors should coordinate and handle the various problems that occur in the evaluation work. At the same time, they should formulate clear rewards and penalties. To actively cooperate with internal control evaluation work to give rewards, to block internal control evaluation behavior to punish. In addition, the board of directors may also hire accounting firms to audit the effectiveness of its internal control, and ensure the quality of the internal control evaluation work.

\section{B. Improving the Internal Control Evaluation System of Listed Companies in China}

Improving the internal control evaluation system of Chinese listed companies is the key to ensure the quality of internal control evaluation. First of all, the main reason for the irregularities in the disclosure of information in internal control evaluation reports lies in the lack of uniform provisions in the contents of internal control evaluation reports. We can study the internal control evaluation reports of listed companies in China. Explore the time, indicators and formats suitable for internal control evaluation reports in China, and then impose the same time, indicators and formats for internal control evaluation reports of listed companies by promulgating relevant regulations. According to the corresponding indicators can be compared, in time to find out the problems existing in the company, put forward solutions. Secondly, we should start with strengthening the supervision and management system for the company's failure to fulfill its information disclosure obligations in time. The purpose of strengthening the internal control evaluation of listed companies by the National regulatory authorities is to promote the improvement of internal control by the mandatory regulation to ensure the healthy development of enterprises.

\section{Improving the Quality of Internal Control Evaluators of Listed Companies}

Improving the quality of the evaluator is the guarantee and foundation of the evaluation work. On the one hand, effective measures should be taken to improve the professional quality of the evaluators. In selecting the evaluation personnel, we should select the independent personnel with strong operational ability to attract the internal control of the enterprise and participate in the daily monitoring of internal control to participate in the evaluation work. In addition, enterprises should also establish a long-term internal control evaluation training mechanism to train internal control evaluation professionals and improve the professional competence of evaluation personnel; On the other hand, we will improve the moral quality of evaluators, strengthen their independence, enable them to do their job objectively and impartially, strengthen professional ethics education for evaluators, and increase the supervision and punishment of their professional ethics, and increase the costs of their violations. At the same time, public opinion is used to supervise whether internal control and evaluation staff are operating illegally, and they are given preventive measures to prevent improper behavior.

\section{CONCLUSIONS}

The internal control evaluation of listed companies is very important to the listed companies themselves and the public. It is urgent to ensure and improve the internal control evaluation of listed companies. This paper analyzes the problems in internal control evaluation of listed companies in China and puts forward its own views on how to improve the quality of internal control evaluation. To conclude that.

First, in view of the fact that the internal control evaluation work of listed companies is not valued, it is proposed that the board of directors or the audit committee should be the main body of the internal control evaluation work in order to coordinate the internal control evaluation work and improve the quality of the internal control evaluation work.

Second, in view of the unreasonable status of internal control evaluation system of listed companies, it is proposed that the internal control evaluation time, index and format should be unified and standardized. For listed companies that fail to disclose according to requirements, penalties should be imposed according to relevant regulations to ensure the quality of internal control evaluation work.

Thirdly, in view of the low quality of evaluators, effective measures should be taken to improve the quality of evaluators. On the one hand, we should make great efforts to improve the professional quality of the evaluators, select those with strong professional ability to participate in the evaluation work, and take effective measures to cultivate and improve the professional competence of the evaluators; On the other hand, we will strengthen the independence of evaluation personnel, strengthen the education, supervision, assessment and punishment of professional ethics, and improve the professional ethics quality of internal control and rating staff.

\section{REFERENCE}

[1] Square plum. Study on Self-Evaluation of Internal Control of Listed Companies in China [D]. Anhui University of Finance and Economics, 2015 .

[2] Xuyao. Status of internal control information disclosure of listed companies and countermeasures [D]. JINLING INSTITUTE OF TECHNOLOGY, 2017.

[3] Fanghongxing, Chi Guohua. Internal control [M], 217 Jianshan Street, Heishijiao, Dalian: Northeast University of Finance and Economics, 2016. 